\title{
The Living Atlases community in action: the GBIF Benin data portal
}

\author{
Anne-Sophie Archambeau ${ }^{\ddagger}$, Fabien Cavière $\ddagger$, Kourouma Koura ${ }^{\S}$, Marie-Elise Lecoq $^{\ddagger}$, Sophie \\ Pamerlon $^{\ddagger}$, Jean C. Ganglo§ \\ ‡ UMS PatriNat - GBIF France, Paris, France \\ $\S$ Laboratoire des Sciences Forestières, Faculté des Sciences Agronomiques, Université d'Abomey-Calavi, Abomey-Calavi, \\ Benin
}

Corresponding author: Marie-Elise Lecoq (melecoq@gbif.fr)

Received: 04 Apr 2018| Published: 21 May 2018

Citation: Archambeau A, Cavière F, Koura K, Lecoq M, Pamerlon S, Ganglo J (2018) The Living Atlases community in action: the GBIF Benin data portal. Biodiversity Information Science and Standards 2: e25488. https://doi.org/10.3897/biss.2.25488

\section{Abstract}

Atlas of Living Australia (ALA) (https://www.ala.org.au/) is the Global Biodiversity Information Facility (GBIF) node of Australia. They developed an open and free platform for sharing and exploring biodiversity data. All the modules are publicly available for reuse and customization on their GitHub account (https://github.com/AtlasOfLivingAustralia).

GBIF Benin, hosted at the University of Abomey-Calavi, has published more than 338000 occurrence records from 87 datasets and 2 checklists. Through the GBIF Capacity Enhancement Support Programme (https://www.gbif.org/programme/82219/capacityenhancement-support-programme), GBIF Benin, with the help of GBIF France, is in the process of deploying the Beninese data portal using the GBIF France back-end architecture. GBIF Benin is the first African country to implement this module of the ALA infrastructure.

In this presentation, we will show you an overview of the registry and the occurrence search engine using the Beninese data portal. We will begin with the administration interface and how to manage metadata, then we will continue with the user interface of the registry and how you can find Beninese occurrences through the hub. 


\section{Presenting author}

Marie-Elise Lecoq 